\title{
Associations of glycated hemoglobin (HbA1c) level with central corneal and macular thickness in diabetic patients without macular edema
}

\author{
Kuddusi Teberik, Mehmet Tahir Eski, Murat Kaya \\ Department of Ophthalmology, Düzce University School of Medicine, Düzce, Turkey
}

DOI: $10.18621 /$ eurj.362263

\begin{abstract}
Objectives: To determine the correlation between central corneal thickness (CCT) and central macular thickness (CMT), and fasting plasma glucose levels and HbA1c levels before diabetic macular edema (DME) in type 2 diabetes mellitus (DM) patients without diabetic retinopathy.

Methods: Forty-four eyes of subjects diagnosed with type $2 \mathrm{DM}$, and 45 healthy control subjects participated in this study. Detailed ophthalmologic examination was performed with all participants. CMT was measured in both groups by Spectral-domain optical coherence tomography. CCT measurements were made with an Echoscan US-500 ultrasonic pachymeter. Blood biochemical tests for glycated hemoglobin (HbA1c) and fasting plasma glucose levels were run on all patients.

Results: The results of the study showed that the mean CCT was significantly thicker in type 2 DM patients $563.84 \pm 33.25 \mu \mathrm{m}$ than in the controls $550.13 \pm 28.41 \mu \mathrm{m}(p=0.039)$. The mean of CMT was $231.27 \pm 37.74$ $\mu \mathrm{m}$ in the study group and $225.38 \pm 38.33 \mu \mathrm{m}$ in the control group $(p>0.05)$. No relationship was found between CCT and CMT and HbAlc level in the study and control groups.

Conclusions: The mean CCT was significantly thicker in type 2 DM patients without diabetic retinopathy than in the controls. The mean CMT is thicker in type $2 \mathrm{DM}$ patients without diabetic retinopathy patients than in the controls, but this difference was not statistically significant. Optical coherence tomography can be a perfect detector for early detection of DME.
\end{abstract}

Keywords: Diabetic macular edema, HbA1c, fasting plasma glucose levels, central corneal thickness, central macular thickness

Received: December 5, 2017; Accepted: December 24, 2018; Published Online: March 31, 2018

D iabetic retinopathy is defined as a particular microvascular complication of diabetes and is the major reason of vision loss within the preferred populace in many nations, together with the employed adult population and the old aged [1-4]. It was estimated that diabetic retinopathy would spread to more than 200 million people around the world by 2012 [5]. It was estimated that in 2000, the spread rate of diabetes for all age groups worldwide would be $2.8 \%$ and $4.4 \%$ in 2030 . It is thought that the number of patients with diabetes all over the world will increase from 171 million in 2000 to 366 million in 2030 [6].

Diabetes is associated with alterations in multiple layers of the retina. For example, it is observed that vascular leak $[7,8]$ and therefore diabetic retinopathy

Address for correspondence: Kuddusi Teberik, MD., Assistant Professor Düzce University School of Medicine, Department of Ophthalmology, Düzce, Turkey

E-mail: kuddusiteberik@yahoo.com,Phone:+90 50563613 15, Fax:+903805421387 
are caused by pericyte loss [9] and vascular endothelial damage [10].

Diabetic macular edema (DME) is the leading reason for visual acuity impairment in diabetic patients. DME is characterised by increased vascular permeability and accumulation of hard exudate in the central retina. DME can be seen at any phase of diabetic retinopathy [11]. DME has been noted to be seen in $10 \%$ of cases and is more common in type 2 diabetes mellitus (DM) than in type 1 [12]. DME affects the whole body adversely by prolonging the duration of diabetes, worsening glycemic control, increasing systolic blood pressure and serum lipids [13]. One way in which diabetic retinopathy can be prevented is through the systemic control of glycemia and tension in diabetic patients $[2,14]$. The Diabetes Control and Complications Trial (DCCT) [15] and the United Kingdom Prospective Diabetes Study (UKPDS) [16] asserted that a tighter control of glycemia (intended glycated hemoglobin [HbA1c] level of $<7 \%$ ) decrease the risk of growth and evolution of diabetic retinopathy and DME in type 1 DM and type 2 DM.

In diabetic cases, neovascular glaucoma, optical neuropathy, and front segment complications can also be observed besides retinopathy. $47-64 \%$ of diabetic patients show indications of corneal epitheliopathy even if it is not clinically a top priority [17]. Diabetesrelated ocular surface and tear changes including corneal epitheliopathy are defined as "diabetic keratopathy" $[17,18]$. There are corneal epithelial defects, recurrent corneal erosions, delayed epithelial recovery, corneal ulcer and dry eye disease in this range. Many studies point out that neurotrophic keratopathy is the main reason for corneal epithelial changes [19-21]. Despite the evidence of corneal epithelium and ocular surface changes in diabetic keratopathy, there are also wrinkles in the Descemet membrane and malformation and malfunction of the corneal endothelium [17, 18]. Increase in corneal stromal edema and central corneal thickness are observed more frequently in diabetic cases [22-24]. The increase in CCT has been claimed by some studies to be one of the earliest symptoms of the diabetic eye [25].

The aim of this study is to determine the correlation between CMT and CCT, and fasting plasma glucose levels and $\mathrm{HbA} 1 \mathrm{c}$ levels before DME becomes clinically apparent in type 2 diabetic patients.

\section{METHODS}

Forty-four eyes of subjects diagnosed with type 2 DM, who were being followed by the endocrinology clinic, and 45 healthy control subjects participated in this study between January 2017 to June 2017. According to the principle of the declaration of Helsinki, the study was explained to the subjects and they were asked to sign a written informed consent. The research was approved by the local ethics committee. Information about the duration of diabetes was by self-report based on the date of detection by a medical practitioner. On each patient's first visit, a detailed systemic and ophthalmological medical history was taken, visual acuity was measured with the chart at 4 meters, a slit-lamp examination was performed, intraocular pressure was measured with Goldmann applanation tonometry, and a dilated fundus examination with a 90D lens was undertaken.

The central macular thickness (CMT) was measured in both groups by Spectral-domain optical coherence tomography (Heidelberg Engineering, Heidelberg, Germany). The CMT was measured after providing pupil dilation with tropicamide drops 2 times, 10 minutes before measurements (Tropicamide 1\%, Alcon Lab. Inc., USA). After receiving measurements with spectral-domain optical coherence tomography, $0.5 \%$ proparacaine hydrochloride (Alcaine, Alcon Laboratories Inc., Fort Worth, TX, ABD) was applied for topical anesthesia. Approximately 5 minutes later, CCT measurements were made with an Echoscan US-500 ultrasonic pachymeter (Nidek Co. Ltd, Aichi, Japan). Participants were asked to fix their gaze on a target during contact measurements, and the pachymetry probe was placed in the central cornea as steeply and gently as possible. During contact process, the probe tips and the double prism were disinfected with 3\% hydrogen peroxide. Measurements were taken in the morning (between the hours of 9:00 am and 11:00 am). All procedures were performed by the same physician. Blood biochemical tests for HbAlc and fasting plasma glucose levels were run on all patients. All cases were subjected to HbAlc testing on the day of the ophthalmic examination. 
Exclusion criteria included patients who received intraocular surgery (cataract surgery, pars plana vitrectomy, intravitreal injection of triamcinolone or Bevacizumab), keratoconus, contact lens use, glaucoma, dry eye, pseudoexfoliation syndrome, previous anterior segment surgery, rubeosis iridis, subtenon injection, photocoagulation therapy within 1 year of evaluation and severe vitreous hemorrhage or vitreous opacity that would interfere with the optical coherence tomography examination. Inclusion criteria for the study group included no visible findings of diabetic retinopathy (hard-soft exudate, microaneurysms) on retina at slit-lamp fundus examination with a +90D lens, type $2 \mathrm{DM}$, no other problems (such as hypertension, uveitis), and no history of ocular trauma, and high refractive errors (spherical equivalent between $+1.00 \mathrm{D}$ and $-1.00 \mathrm{D}$ ). Inclusion criteria for the control group patients included no ophthalmologic or systemic problems, no history of intraocular surgery or treatment of the retina, and no high refractive errors (spherical equivalent: between $-1.0 \mathrm{D}$ and $+1.0 \mathrm{D}$ ).

\section{Statistical Analysis}

Statistical analyses were performed with SPSS 18.0 software (SPSS Inc., Chicago, IL, USA). Gender distribution between the groups was investigated by a chi-square test. The distribution of age and HbAlc values were evaluated by one-way ANOVA. Independent sample tests were used to compare the means between the diabetic and control groups. Pearson's correlationanalyses were conducted to evaluate the relationship between the parameters showing normal distribution, and Spearman's rho correlation analyses have been used to evaluate the correlation between the parameters not showing normal distribution. The level of significance was set at $p<0.05$.

\section{RESULTS}

Of the 44 Type $2 \mathrm{DM}$ patients included in the study, 24 were male (54.5\%) and $20(45.5 \%)$ were female and the mean age was $60.11 \pm 8.17$ (47-76). Twenty-one $(46.7 \%)$ of the control group were male and $24(53.3 \%)$ were female and the mean age was $59.40 \pm 5.1$ years (range, 50-70 years). There were no differences in sex, age and best corrected visual acuity (BCVA) between the groups ( $p>0.05)$.

The results of the study showed that the mean CCT was significantly thicker in type $2 \mathrm{DM}$ patients $563.84 \pm 33.25 \mu \mathrm{m}$ than in the controls $550.13 \pm 28.41$ $\mu \mathrm{m}(p=0.039)$. The mean of CMT was $231.27 \pm 37.74$ $\mu \mathrm{m}$ in the study group and $225.38 \pm 38.33 \mu \mathrm{m}$ in the control group $(p>0.05)$.

The mean HbA1c level was $7.92 \pm 1.69 \%$ in the study group and $5.18 \pm 0.51 \%$ in the control group. The mean level of HbA1c was statistically higher in the study group than in the control group $(p=0.001)$. Fasting plasma glucose level was statistically higher in the study group than in the control group $(p=$ $0.001)$. The duration of diabetes mellitus was $13.45 \pm$ 5.5 years (range, 3-27 years) (Table 1).

No correlation was found between CCT and fasting plasma glucose level in the study $(p=0.415)$ and control $(p=0.342)$ groups. No relationship was found between CCT and $\mathrm{HbA} 1 \mathrm{c}$ level in the study $(p$

Table 1. Demographic characteristics, values for CCT, CMT, and biochemical analysis in patients with type

2 diabetes without clinical retinopathy

\begin{tabular}{lccc}
\hline Parameters & $\begin{array}{c}\text { Study group } \\
(\boldsymbol{n}=\mathbf{4 4})\end{array}$ & $\begin{array}{c}\text { Control group } \\
(\boldsymbol{n}=\mathbf{4 5})\end{array}$ & $\boldsymbol{p}$ value \\
\hline BCVA (logMAR) & 0 & 0 & $\mathrm{NS}$ \\
IOP (mmHg) & $15.0 \pm 2.7$ & $15.8 \pm 2.1$ & $\mathrm{NS}$ \\
Age (years) & $60.11 \pm 8.17$ & $59.40 \pm 5.1$ & $\mathrm{NS}$ \\
Male/ Female & $24 / 20$ & $21 / 24$ & $\mathrm{NS}$ \\
CCT $(\boldsymbol{\mu m})$ & $563.84 \pm 33.25$ & $550.13 \pm 28.41$ & $\mathbf{0 . 0 3 9}$ \\
CMT $(\boldsymbol{\mu m})$ & $231.27 \pm 37.74$ & $225.38 \pm 38.33$ & $\mathrm{NS}$ \\
HbA1c $(\mathbf{\%})$ & $7.92 \pm 1.69$ & $5.18 \pm 0.51$ & $\mathbf{0 . 0 0 1}$ \\
Fasting blood glucose level $(\mathbf{m g} / \mathbf{1 0 0} \mathbf{~ m l})$ & $213.09 \pm 81.28$ & $89.46 \pm 13.92$ & $\mathbf{0 . 0 0 1}$
\end{tabular}

Data are shown as mean \pm standard deviation or number. BCVA = best corrected visual acuity, CCT $=$ central corneal thickness, CMT = central macular thickness, Control group = healthy subjects, HbA1c = glycated hemoglobin, IOP $=$ Intraocular pressure, $\log \mathrm{MAR}=$ logarithm of the minimum angle of resolution, $\mathrm{NS}=$ nonsignificant, Study group = patients with type 2 diabetes without clinical retinopathy 
Table 2. Relationship between CCT, CMT, HbA1c, fasting blood glucose levels, and duration of DM in patients with type 2 diabetes without clinical retinopathy

\begin{tabular}{lcccc}
\hline Parameters & \multicolumn{2}{c}{ Study group } & \multicolumn{2}{c}{ Control group } \\
& $\mathbf{r}$ & $\boldsymbol{p}$ value & $\mathbf{r}$ & $\boldsymbol{p}$ value \\
\hline CCT-HbA1c & 0.284 & 0.062 & 0.122 & 0.424 \\
CCT-fasting plasma glucose level & 0.126 & 0.415 & 0.145 & 0.342 \\
CCT-duration of DM & 0.077 & 0.617 & - & - \\
CMT-HbA1c & -0.031 & 0.841 & 0.025 & 0.870 \\
CMT-fasting plasma glucose level & $-0,07$ & 0.649 & 0.111 & 0.469 \\
CMT-duration of DM & 0.074 & 0.634 & - & - \\
\hline
\end{tabular}

$\mathrm{CCT}=$ central corneal thickness, CMT = central macular thickness, Control group = healthy subjects, DM $=$ diabetes mellitus, HbA1c $=$ glycated hemoglobin, $r=$ relation between two variables, Study group $=$ patients with type 2 diabetes without clinical retinopathy,

$=0.062)$ and control groups $(p=0.424)$. No relationship was found between CMT and fasting plasma glucose level in the study $(p=0.649)$ and control $(p=0.469)$ groups. No relationship was found between CMT and HbA1c level in the study $(p=$ $0.841)$ and control groups ( $p=0.870$; Table 2$)$.

\section{DISCUSSION}

DM can affect almost all ocular structure. DM does not only lead to an ocular complication, diabetic retinopathy, but it is also believed to lead to some changes in the anterior segment of the eye [26, 27]. Examples of these abnormalities are a decrease in endothelial cell density and hexagonality, and an increase in polymegathism, pleomorphism and CCT $[23,28]$. In this study, ultrasonic pachymeter examinations were performed in type 2 diabetic patients without DME. The mean CCT was significantly thicker in type $2 \mathrm{DM}$ patients than in the controls. Additionally, no statistically significant relationship was found between $\mathrm{CCT}, \mathrm{HbAlc}$, and fasting plasma glucose level in either group.

Many studies have used specular microscopy and shown that DM-diagnosed patients have many structural changes in the corneal endothelium compared to healthy individuals $[29,30]$. It is stated that hyperglycemia affects the corneal thickness in diabetic patients by impairing corneal hydration, thereby destroying the corneal structure by McNamara et al. [32]. Schultz et al. [29] examined the barrier and pump function of corneal endothelium using a fluorometric method and found that there were some deficiencies as a result. Consequently, it has been claimed that change in corneal thickness is common in patients with DM. As reported by the results of Herse's experimental study [32], the evaluated fall in $\mathrm{Na}+/ \mathrm{K}+$ ATPase activity of diabetic rabbits proves that abnormal corneal hydration system of the diabetic rabbits which are not controlled is managed by a functional disorder of endothelial fluid pump. The biological basis of corneal changes in the eyes of diabetic patients is not yet found and the underlying mechanisms are still unknown. Su et al. [33] studied the association of diabetes and hyperglycemia with CCT in 3239 eyes where 748 diabetic patients participated and showed a $6.5 \mu \mathrm{m}$ thicker CCT than the healthy group in non-diabetic patients. Lee et al. [23] found that CCT was higher in patients with DM than in the control group, as a result of studying the CCT of diabetic patients with normal fundus and DR history. Inoue et al. [24] and Choo et al. [11] reported that diabetic group CCT data did not show any significant difference from control groups. According to the results of the study conducted by Ozdamar et al. [34], CCT values in diabetic group were significantly higher than the control group. The same study shows no correlation between $\mathrm{HbAlc}$ and CCT. Although HbAlc is a marker of long-term DM control, we assume that high glucose levels may lead to corneal thickening than at any other time in the life of a diabetic patient.

The relationship between $\mathrm{CMT}, \mathrm{HbA1c}$ and fasting plasma glucose levels was also observed in patients with type 2 diabetes who did not have clinical diabetic retinopathy in our study. Although the mean CMT was thicker in type $2 \mathrm{DM}$ patients without diabetic retinopathy compared to healthy subjects, this difference was not statistically significant. There was no positive correlation between fasting plasma glucose level and CMT in patients with diabetes mellitus and 
without retinopathy. CMT was not increased by mild or high levels of HbA1c $(7.92 \pm 1.69 \%)$. CCT and CMT were not affected by the duration of diabetes mellitus in patients with diabetes type 2 without retinopathy.

Browning et al. [35] reported in their study that in patients without clinically macular edema in spite of being diagnosed with diabetic retinopathy, especially the variations in central subfield macular thickness and total macular volume (TMV) in optical coherence tomography were not greater than the measurement variation in eyes with or without DME. It was stated that the changes, which are more than $10 \%$ compared to the initial macular thickness, should be considered as a real change, whereas the remaining values could be due to measurement variations, diurnal variations, or variations of the long-lasting scale. Sugimoto et al. [36] found that the retinal thickness increased and the retinal nerve fiber layer thickness decreased in the superior quadrant in the eyes of patients with nondiabetic retinopathy in the study they tried to confirm early diabetic injury and evaluate optical coherence tomography as a clinical test. They also reported that it is possible to detect early signs and structural changes with optical coherence tomography at a much earlier stage and that optical coherence tomography can be used in early treatment planning. Bressler et al. [37] determined in their studies evaluating macular thickness with optical coherence tomography in type 1 and type 2 diabetic patients without retinopathy or with very mild retinopathy and no macular thickening on clinical examination that the macular thickness values of these diabetic patients without retinopathy or with very mild retinopathy were similar to those of normal individuals but found that the average central subfield thickness in males was statistically significantly higher than that of females $(209 \pm 18 \mu \mathrm{m}$ vs. $194 \pm 23 \mu \mathrm{m})$.

Glycemic control is critical for DM treatment and can be assessed periodically by HbA1c measurement. Chou et al. [11] demonstrated that $8 \%$ or more of $\mathrm{HbA1c}$ in diabetic retinopathy-diagnosed diabetic patients is associated with an increase in macular thickness. Moreira et al. [38] demonstrated that no other variables other than $\mathrm{HbA1c}$ were associated significantly with macular edema. According to the findings of the Los Angeles Latino Eye Study (LALES), there is a $22 \%$ increase in the spread of diabetic retinopathy and a $1 \%$ increase in HbAlc level [39]. The Wisconsin Epidemiology Study of Diabetic Retinopathy (WESDR) reported that the presence of high levels of HbA1c increased the risk of developing DME within a 10-year period [40]. The most widely accepted pathophysiological model for diabetic retinopathy development involves microvascular dysfunction. Abnormalities in glucose metabolism lead to changes in the capillary vessels of the retina and deterioration of the blood/retinal barrier, resulting in microaneurysms, hemorrhages, and retinal exudate. These retinal changes cause retinal thickening that can be detected with 0 ptical coherence tomography. Since HbAlc levels were recorded for only 3 months, it is difficult for this study to determine whether the positive correlation between chronic HbAlc level and macular thickness is more harmful to microvasculature caused by high chronic hyperglycemia.

\section{The Limitations of the Study}

There are limitations to the study. One of these is the small sample size in both groups and another is that none of the patients had diabetes mellitus for longer than 20 years.

\section{CONCLUSION}

In this study, the mean CCT was significantly thicker in type $2 \mathrm{DM}$ patients without diabetic retinopathy than in the controls. The mean CMT is thicker in type $2 \mathrm{DM}$ patients without diabetic retinopathy than in the controls, but this difference was not statistically significant. No correlation between HbA1c, fasting plasma glucose levels and duration of DM was found with both CCT and CMT. Optical coherence tomography can be a perfect detector for early detection of DME.

\section{Conflict of interest}

The authors disclosed no conflict of interest during the preparation or publication of this manuscript.

\section{Financing}

The authors disclosed that they did not receive any grant during conduction or writing of this study. 


\section{REFERENCES}

[1] Antonetti DA, Klein R, Gardner TW. Diabetic retinopathy. N Engl J Med 2012;366:1227-39.

[2] Cheung N, Mitchell P, Wong TY. Diabetic retinopathy. Lancet 2010;376: 24-36.

[3] Klein R, Lee KE, Gangnon RE, Klein BE. The 25-year incidence of visual impairment in type 1 diabetes mellitus. the wisconsin epidemiologic study of diabetic retinopathy. Ophthalmology 2010;117 63-70.

[4] Moss SE, Klein R, Klein BE. The 14-year incidence of visual loss in a diabetic population. Ophthalmology 1998;105:998-1003.

[5] Chu J, Ali Y. Diabetic retinopathy. Drug Deve Res 2008;69:1-14.

[6] Wild S, Roglic G, Greene A. Global prevalence of diabetes: estimates for the year 2000 and projections for 2030. Diabetes Care 2004;27:104753.

[7] Matsuura H, Setogawa T, Tamai A. Electron microscopic studies on retinal capillaries in human diabetic retinopathy. Yonago Acta Med 1976;20:7-10.

[8] Antonetti DA, Lieth E, Barber AJ, Gardner TW. Molecular mechanisms of vascular permeability in diabetic retinopathy. Semin Ophthalmol 1999;14:240-8.

[9] de Oliveira F. Pericytes in diabetic retinopathy. Br J Ophthalmol 1966;50:134-43.

[10] Craitoiu S, Mocanu C, Olaru C, Rodica M. Retinal vascular lesions in diabetic retinopathy. Oftalmologia 2005;49:82-7.

[11] Chou TH, Wu PC, Kuo JZ, Lai CH, Kuo CN. Relationship of diabetic macular oedema with glycosylated haemoglobin. Eye (Lond) 2009;23:1360-3.

[12] GirachA, Lund-Andersen H. Diabetic macular oedema: a clinical overview. Int J Clin Pract 2007;61:88-97.

[13] Wat N, Wong RL, Wong IY. Associations between diabetic retinopathy and systemic risk factors. Hong Kong Med J 2016;22:58999.

[14] Frank RN. Diabetic retinopathy. N Engl J Med 2004;350:48-58.

[15] The Diabetes Control and Complications Trial Research Group. The effect of intensive treatment of diabetes on the development and progression of long-term complications in insulin-dependent diabetes mellitus. N Engl J Med 1993;329:977-86.

[16] UK Prospective Diabetes Study (UKPDS) Group. Intensive bloodglucose control with sulphonylureas or insulin compared with conventional treatment and risk of complications in patients with type 2 diabetes. Lancet 1998;352:837-53.

[17] Schultz RO, Van Horn DL, Peters MA, Klewin KM, Schutten WH. Diabetic keratopathy. Trans Am Ophthalmol Soc 1981;79:180-99.

[18] Kaji Y. Prevention of diabetic keratopathy. Br J Ophthalmol 2005;89:254-5.

[19] Saito J, Enoki M, Hara M, Morishige N, Chikama T, Nishida T. Correlation of corneal sensation, but not of basal or reflex tear secretion, with the stage of diabetic retinopathy. Cornea 2003;22:15-8.

[20] Zhivov A, Winter K, Hovakimyan M, Peschel S, Harder V, Schober $\mathrm{HC}$, et al. Imaging and quantification of subbasal nerve plexus in healthy volunteers and diabetic patients with or without retinopathy. PLoS One 2013;8:e52157.

[21] Chang PY, Carrel H, Huang JS, Wang IJ, Hou YC, Chen WL, et al. Decreased density of corneal basal epithelium and subbasal corneal nerve bundle changes in patients with diabetic retinopathy. Am Ophthalmol 2006;142:488-90.

[22] Siribunkum J, Kosrirukvongs P, Singalavanija A. Corneal abnormalities in diabetes. J Med Assoc Thai 2001;84:1075-83.
[23] Lee JS, Oum BS, Choi HY, Lee JE, Cho BM. Differences in corneal thickness and corneal endothelium related to duration in diabetes. Eye 2006;20:315-8.

[24] Inoue K, Kato S, Inoue Y, Amano S, Oshika T. The corneal endothelium and thickness in type II diabetes mellitus. Jpn J Ophthalmol 2002;46:65-9.

[25] Busted N, Olsen T, Schmitz O. Clinical observations on the corneal thickness and the corneal endothelium in diabetes mellitus. $\mathrm{Br} \mathrm{J}$ Ophthalmol 1981;65:687-90.

[26] Wiemer NG, Dubbelman M, Kostense PJ, Ringens PJ, Polak BC. The influence of chronic diabetes mellitus on the thickness and the shape of the anterior and posterior surface of the cornea. Cornea 2007;26:116570 .

[27] Wiemer NG, Dubbelman M, Hermans EA, Ringens PJ, Polak BC. Changes in the internal structure of the human crystalline lens with diabetes mellitus type 1 and type 2. Ophthalmology 2008;115:2017-23. [28] Shenoy R, Khandekar R, Bialasiewicz A, Al Muniri A. Corneal endothelium in patients with diabetes mellitus: a historical cohort study. Eur J Ophthalmol 2009;19:369-75.

[29] Schultz RO, Matsuda M, Yee R, Edelhauser HF, Schultz KJ. Corneal endothelial changes in type 1 and 2 diabetes mellitus. Am J Ophthalmol 1984;98:401-10.

[30] Torun B, Ülkü G, Yılmaz T. [Evaluation of central corneal thickness in patients with diabetes mellitus]. Firat Tip Dergisi 2010;15:128-30. [Article in Turkish]

[31] McNamara NA, Brand RJ, Polse KA, Bourne WM. Corneal function during normal and high serum glucose levels in diabetes. Invest Ophthalmol Vis Sci 1998;39:3-17.

[32] Herse PR. Corneal hydration control in normal and alloxan induced diabetic rabbits. Invest Ophthalmol Vis Sci 1990;31:2205-13.

[33] Su DH, Wong TY, Wong WL, Saw SM, Tan DT, Shen SY, et al. Singapore Malay Eye Study Group. Diabetes, hyperglycemia, and central corneal thickness: the Singapore Malay Eye Study. Ophthalmology 2008;115:964-8.

[34] Ozdamar Y, Cankaya B, Ozalp S, Acaroglu G, Karakaya J, Ozkan $\mathrm{SS}$. Is there a correlation between diabetes mellitus and central corneal thickness? J Glaucoma 2010;19:613-6.

[35] Browning DJ, Fraser CM, Propst BW. The variation in optical coherence tomography-measured macular thickness in diabetic eyes without clinical macular edema. Am J Ophthalmol 2008;145:889-93.

[36] Sugimoto M, Sasoh M, Ido M, Wakitani Y, Takahashi C, Uji Y. Detection of early diabetic change with optical coherence tomography in type 2 diabetes mellitus patients without retinopathy. Ophthalmologica 2005;219:379-85.

[37] Bressler NM, Edwards AR, Antoszyk AN, Beck RW, Browning DJ, Ciardella AP, et al. Diabetic Retinopathy Clinical Research Network. Retinal thickness on Stratus optical coherence tomography in people with diabetes and minimal or no diabetic retinopathy. Am J Ophthalmol 2008;145:894-901.

[38] Moreira RO, Trujillo FR, Meirelles RM, Ellinger VC, Zagury L. Use of optical coherence tomography (OCT) and indirect ophthalmoscopy in the diagnosis of macular edema in diabetic patients. Int Ophthalmol 2001;24:331-6.

[39] Varma R, Macias GL, Torres M, Klein R, Klein R, Peña FY, et al.; Los Angeles Latino Eye Study Group. Biologic risk factors associated with diabetic retinopathy: the Los Angeles Latino Eye Study. Ophthalmology 2007;114:1332-40.

[40] Klein R, Klein BEK, Moss SE, Cruickshanks KJ. The Wisconsin Epidemiologic Study of Diabetic Retinopathy. XV. The long-term incidence of macular edema. Ophthalmology 1995;102:7-16. 